\title{
Glaucoma associated with the management of rhegmatogenous retinal detachment
}

This article was published in the following Dove Press journal:

Clinical Ophthalmology

12 April 2013

Number of times this article has been viewed

\section{George Mangouritsas \\ Spyridon Mourtzoukos \\ Dimitra M Portaliou \\ Vassilios I Georgopoulos \\ Anastasia Dimopoulou \\ Elias Feretis}

Eye Clinic, General Hospital "Hellenic Red Cross”, Athens, Greece
Correspondence: George Mangouritsas Consultant Ophthalmologist, Glaucoma Department, Eye Clinic, General Hospital "Hellenic Red Cross", I, Erythrou Stavrou Str, 11526 Athens, Greece Tel +30 6944385238

Email maguritsas@gmail.com

\begin{abstract}
Transient or permanent elevation of intraocular pressure (IOP) is a common complication following vitreoretinal surgery. Usually secondary glaucoma, which develops after scleral buckling procedures, or pars plana vitrectomy for repair of rhegmatogenous retinal detachment, is of multifactorial origin. It is essential, for appropriate management, to detect the cause of outflow obstruction. An exacerbation of preexisting open-angle glaucoma or a steroid-induced elevation of IOP should also be considered. Scleral buckling may be complicated by congestion and anterior rotation of the ciliary body resulting in secondary angle closure, which can usually resolve with medical therapy. The use of intravitreal gases may also induce secondary angle-closure with or without pupillary block. Aspiration of a quantity of the intraocular gas may be indicated. Secondary glaucoma can also develop after intravitreal injection of silicone oil due to pupillary block, inflammation, synechial angle closure, or migration of emulsified silicone oil in the anterior chamber and obstruction of the aqueous outflow pathway. In most eyes medical therapy is successful in controlling IOP; however, silicone oil removal with or without concurrent glaucoma surgery may also be required. Diode laser transscleral cyclophotocoagulation and glaucoma drainage devices constitute useful treatment modalities for long-term IOP control. Cooperation between vitreoretinal and glaucoma specialists is necessary to achieve successful management.
\end{abstract}

Keywords: retinal detachment, intraocular pressure elevation, glaucoma, vitrectomy, intravitreal gas, silicone oil

\section{Introduction}

Various mechanisms associated with vitreoretinal reattachment surgery can lead to a significant decrease or even blockage of aqueous outflow, resulting in different types of secondary glaucoma. Determining the underlying cause of intraocular pressure (IOP) elevation is crucial for successful management. Gonioscopy is an integral part of the comprehensive examination of these eyes in order to distinguish between angle closure and trabecular meshwork obstruction. Preexisting open-angle glaucoma or a steroid-induced rise in IOP has to be differentiated from an IOP elevation, which is a direct consequence of the surgical procedure.

There is insufficient clarity with regard to the nomenclature of IOP elevation, ocular hypertension, and glaucoma following retinal detachment surgery. A transient rise in IOP - promptly treated, with no evident effect on the optic nerve and visual function - should be described solely as a postoperative IOP elevation. A chronically, directly associated with the surgical procedure, elevated IOP resulting in typical damage of the optic nerve and characteristic loss of the visual field should be considered as 
secondary glaucoma. In addition, a postoperative IOP elevation leading occasionally to the manifestation of secondary glaucoma should not be characterized as ocular hypertension. The later term indicates that the IOP is consistently outside two standard deviations from the normal mean, with all other ocular findings falling within normal limits, and this represents a clinical entity associated with a higher risk of developing primary open-angle glaucoma (POAG).

This article provides an overview of the incidence, pathophysiology, and management of IOP elevation or glaucoma following scleral buckling procedures and pars plana vitrectomy (PPV) with gas or silicone oil (SO) tamponade for rhegmatogenous retinal detachment. This study has been conducted because of the scarcity of recent published information on this topic; it also aims to highlight the importance of glaucoma management after vitreoretinal surgery. It is conceivable that in such cases delayed detection or suboptimal monitoring of the optic nerve damage may occur due to the emphasis placed upon the successful reattachment of the retina.

\section{Preexisting open-angle glaucoma}

Glaucoma after vitreoretinal surgery is usually secondary; however, a preoperatively undetected POAG or an exacerbation of a preexisting ocular hypertension should also be considered. A link between POAG and primary retinal detachment has been previously reported. Phelps and Burton ${ }^{1}$ found, among 817 patients, that glaucoma preceded the retinal detachment historically or by clinical evidence in almost $7 \%$. One reason for the higher rate of retinal detachment in POAG eyes might be the prevalence of myopia as a common risk factor for both disorders. ${ }^{2,3}$ A possible association between retinal detachments and miotics has also been suggested. ${ }^{4}$ Medical history, an anterior chamber of normal depth, a normal open angle, optic nerve head appearance, and the findings of the fellow eye may contribute to the diagnosis of an unrecognized POAG. A steroid-induced IOP elevation, manifesting with similar characteristics as POAG, has to be excluded.

Eyes with pigment dispersion syndrome, which may develop pigmentary glaucoma, also showed an increased prevalence of lattice changes and retinal detachment. ${ }^{5}$ Pigmentation of the corneal endothelium (Kruckenberg spindle) and of the trabeculum, as well as the typical iris transillumination defects, are signs indicating pigmentary glaucoma. An ordinary examination of the fundus periphery in such patients is warranted. Medical treatment for POAG should be initiated.

\section{Steroid-induced IOP elevation}

Use of topical steroids to treat postoperative inflammation is part of the standard regimen after vitreoretinal procedures. It is well known that administration of dexamethasone $0.1 \%$ or betamethasone $0.1 \%$ for 1 month can cause a rise in IOP greater than $15 \mathrm{mmHg}$ in $5 \%$ of the general population, and a rise of $6 \mathrm{mmHg}$ to $15 \mathrm{mmHg}$ in $30 \%$ of the population. ${ }^{6,7}$ Patients with POAG using topical dexamethasone/ betamethasone $0.1 \%$ demonstrated an ocular hypertensive response in about $90 \% .{ }^{8,9}$ A first-degree relative with POAG, ${ }^{10}$ type 1 diabetes, ${ }^{11}$ and high myopia have also been identified as risk factors for steroid-induced IOP elevation. ${ }^{12}$ In addition, Shammas et $\mathrm{a}^{13}$ found that $20 \%$ of patients with primary retinal detachment had an IOP elevation of more than $15 \mathrm{mmHg}$ after the administration of dexamethasone to the fellow nondetached eye. This finding indicated the possibility that a significant steroid response was higher in individuals with primary retinal detachment than in normal eyes. Consequently a steroid-induced IOP elevation following retinal detachment surgery may be suspected by the presence of the mentioned risk factors and the absence of other causes leading to increased IOP.

The magnitude of the IOP rise induced by a steroid agent depends on its chemical structure. ${ }^{14}$ Dexamethasone acetate $0.1 \%$ induces a higher hypertensive response than prednisolone acetate $1.0 \%$. Loteprednol or fluorometholone may have a lower antiinflammatory effect, and a much lower hypertensive response as well. In eyes predisposed to an ocular hypertensive response, it is preferable to use steroids for a shorter postoperative period. Depending on the severity of postoperative inflammation, switching to a less potent topical steroidal agent may be advisable. A nonsteroidal antiinflammatory agent can be beneficial in preventing cystoid macular edema as well. After discontinuation of steroid drops, IOP usually tends to decrease or return to baseline within a few weeks. Aqueous humor suppressants, such as $\beta$-blockers, carboanhydrase inhibitors, or alpha 2-adrenergic agonists, are recommended as first-line therapy.

\section{Scleral buckling procedures}

Scleral indentation for repairing retinal detachment may be complicated by IOP elevation due to secondary angle closure. It has been previously reported that the incidence of IOP elevation and/or glaucoma after scleral buckling varies from $1.4 \%$ to $4.4 \% .{ }^{15-18}$ Choroidal effusion leads to swelling and anterior rotation of the ciliary body, as well as forward shifting of the lens-iris diaphragm with subsequent narrowing or closure of the angle. These morphological changes have 
been demonstrated experimentally and can be commonly detected by funduscopic examination or by ultrasonography/ ultrasound biomicroscopy. ${ }^{19,20}$ Kawana et al, ${ }^{21}$ by means of ultrasound biomicroscopy, evaluated the ciliary body thickness and anterior chamber depth after scleral buckling procedures, confirming the existence of subclinical ciliary edema for at least 1 month postoperatively. Goezinne et al, ${ }^{22}$ using an anterior optical coherence tomography method and the IOLMaster device (Carl Zeiss Meditec AG, Jena, Germany), found that the anterior chamber depth may remain decreased after scleral buckling for almost 1 year. Choroidal effusion may be induced by compression of the vortex veins due to a broad scleral indentation, by excessive cryoretinopexy, or by drainage of subretinal fluid during surgery. A preexisting narrow angle, the use of a 360-degree buckle, high myopia, and older age have also been reported as risk factors for secondary angle closure..$^{15-18,21}$

In cases with persistently high IOP, medical treatment should be initiated. First-line medications include cycloplegics (relaxation of the ciliary muscle and backward repositioning of the iris-lens diaphragm), topical steroids (prevention of anterior synechiae formation), and aqueous humor suppressants; pilocarpine should be avoided. Laser iridotomy does not seem to be beneficial. In the majority of eyes, the suprachoroidal fluid may subside over a period of a few days or weeks resulting in resolution of the angle closure and the normalization of IOP. If the angle remains closed and the anterior chamber shows no tendency to deepen up to 1 week, a laser iridoplasty should be performed. The peripheral iris is thermally contracted and may result in reopening of the angle and decreasing $\mathrm{IOP}^{23}$

Medical or laser treatment provides usually adequate IOP control. Choroidal drainage combined with repositioning of the scleral buckle in the early postoperative period may be a treatment modality. In patients with chronically uncontrolled IOP, surgical treatment by means of glaucoma drainage devices has been suggested. ${ }^{24-26}$ In cases with encircling bands, implantation of tubes using the fibrous capsule around the buckle as reservoir has been described with good results. ${ }^{24,25}$ The modified drainage devices such as a Baerveldt implant with trimmed off "wings" positioned at the less crowded bulbous quadrant have been demonstrated as a successful alternative. ${ }^{26}$ Cyclodestructive procedures are not considered as a favorable option.

\section{Intravitreal gas injection}

Injection in the vitreous cavity of expansible gases such as sulfur hexafluoride (SF6), perfluoroethane (C2F6), or perfluoropropane $(\mathrm{C} 3 \mathrm{~F} 8)$ has been widely used in pneumatic retinopexy, as well as in vitrectomy and scleral buckle surgery. Compared to air, intraocular gases have the advantage of providing a prolonged tamponade of retinal breaks in order to promote a firm chorioretinal adhesion. ${ }^{27}$

The magnitude of expansion and the longevity of a pure gas injected in the vitreous cavity depend on its chemical structure. ${ }^{28-33}$ The volume of SF6 doubles within 24-48 hours, while $\mathrm{C} 3 \mathrm{~F} 8$ can expand to four times the injected volume within 48-72 hours. The longevity of air, pure SF6, C2F6, or $\mathrm{C} 3 \mathrm{~F} 8$ in the vitreous cavity can be 5-7 days, 2-3 weeks, 4-6 weeks, and 6-8 weeks, respectively.

An expansible gas injected into the vitreous cavity may cause anterior displacement of the iris-lens diaphragm and secondary angle closure. Equilibrated gases diluted with air in concentrations of $20 \%$ for SF $6,16 \%$ for $\mathrm{C} 2 \mathrm{~F} 6$, and $14 \%$ for $\mathrm{C} 3 \mathrm{~F} 8$ may provide a safe tamponade with a lower incidence of IOP elevation. ${ }^{34,35}$ An incidence of IOP elevation higher than $29 \mathrm{mmHg}$ following intravitreal injection of 20\% SF6 and $14 \% \mathrm{C} 3 \mathrm{~F} 8$ was found to be $6.1 \%$ and $18 \%$, respectively. ${ }^{34,35}$

Patients should always be advised to maintain a face-down posture in order to avoid forward displacement of the iris-lens diaphragm. Changes in atmospheric pressure could produce an expansion of the intraocular gas volume and result in an acute IOP increase. ${ }^{36-38}$ Therefore, patients with intravitreal gas injection should be discouraged from traveling to high altitudes. IOP should be measured by using the Goldmann applanation tonometer (Haag-Streit AG, Koeniz, Switzerland) or Perkins tonometer (Haag-Streit AG, Koeniz, Switzerland). Pneumatic and Schiotz' indentation tonometry may underestimate IOP. ${ }^{39-41}$ Mild IOP elevation may occur within the first 24 hours, responding usually to topical aqueous suppressants or oral carbonic anhydrase inhibitors within a few days. In case of gas overfill leading to severe elevation of IOP and compromised ocular perfusion, aspiration of a quantity of the intraocular gas should be performed immediately. ${ }^{42}$ Surgical management using glaucoma drainage devices may be required in some refractory cases. ${ }^{43,44}$ In cases of extensive peripheral synechiae, a posterior insertion of the tube via a new pars plana port can be an alternative.

\section{Pars plana vitrectomy with silicone oil tamponade}

Over the last decades, silicone oil (SO) has been widely used as an adjunct for intraocular tamponade during vitrectomy, ${ }^{45}$ especially in eyes with proliferative vitreoretinopathy (PVR). Development of cataracts, glaucoma, and keratopathy are well-recognized anterior segment complications after PPV 
with SO injection (PPVSOI), occurring even after successful reattachment of the retina. ${ }^{46,47}$ Increase of IOP can occur postoperatively at any time ranging from mild and transient to severe and permanent, resulting occasionally in refractory glaucoma. The incidence of elevated IOP or glaucoma following PPVSOI for complicated retinal detachment of various etiologies ranges between $4.8 \%$ and $48 \%{ }^{48-60}$ In recent studies, this incidence rate has been found to be lower than previously reported, probably due to improvement of surgical techniques and refinement of surgical materials. The significant variations among retrospective studies could also be explained by the discrepancies of the inclusion criteria regarding the cause, onset, duration, and level of postoperative IOP elevation, or due to the different kinematic viscosities of SO.

In the prospective Silicone Study, ${ }^{53}$ the incidence of chronic IOP elevation in 241 eyes with PVR managed by PPVSOI was found in $8 \%$ of patients. Henderer et $\mathrm{al}^{56}$ found that among 383 eyes, PPVSOI-sustained IOP $(>25 \mathrm{mmHg})$ was evident in $12.9 \%$ of patients at 6 months and $29.5 \%$ of patients at 2 years, whereas diabetic patients with proliferative diabetic retinopathy had a higher risk of elevated IOP than those with isolated PVR. A lower incidence of increased IOP after PPVSOI for PVR has been reported in several studies. ${ }^{49-51,54}$ Jonas et $\mathrm{al}^{57}$ demonstrated that $20 \%$ of 198 patients had at least one postoperative IOP measurement $>21 \mathrm{mmHg}$, whereas glaucomatous optic nerve damage was detected only in 14 (7.1\%) eyes, including eight eyes with preoperative antiglaucoma treatment. Recently, it has been reported that in a series of 450 eyes treated with PPVSOI, 51 eyes (11\%) developed an IOP $\geq 21 \mathrm{mmHg}$, which was sustained for 6 weeks or longer. ${ }^{60}$ Apparently, all these data suggest that a secondary mild and transient IOP elevation after PPVSOI - especially in eyes with PVR detachment - is not uncommon, whereas a small percentage of eyes (probably less than 10\%) end up with chronic glaucoma, which may raise therapeutic concerns.

Several factors that are predictive of IOP elevation following PPVSOI have been reported, and these include preexisting ocular hypertension or glaucoma, diabetes mellitus, and aphakia. ${ }^{55,56,60}$

It remains controversial, whether the duration of SO tamponade, migration of silicone in the anterior chamber, or its viscosity are significantly associated with glaucoma development. ${ }^{47,50,52,55-57,60-69}$

A heavier than water $\mathrm{SO}$ - such as Densiron 68 (Fluoron, Neu - Ulm, Germany) or Oxane HD (Bausch \& Lomb UK Limited, London, UK) - which has been developed to improve tamponade in eyes with PVR of the inferior retina, showed comparable to conventional SO surgical outcomes and side effects. ${ }^{70,71} \mathrm{SO}$-related mechanisms can induce postoperative IOP elevation either immediately or in the longterm, and may lead to glaucomatous optic neuropathy. ${ }^{72}$

Early postoperative IOP increases may be caused by severe inflammation, ${ }^{52,73}$ or most often by pupillary block, ${ }^{47,49,51,52,55-57,64,74,75}$ leading to secondary angle closure, or to the migration of SO in the anterior chamber resulting in mechanical obstruction of the aqueous outflow. Preexisting glaucoma or steroid-induced IOP elevation, as aforementioned, should also be considered. In the presence of a pupillary block, the aqueous humor, which accumulates at the lowest part of the posterior segment behind the iris, may push SO through the pupil into the anterior chamber. This can occur more frequently in aphakic eyes, if the iridectomy at the 6 o'clock position (Ando's iridectomy) has been improperly performed, ${ }^{76}$ or closed due to postoperative fibrinous reaction. The overall incidence of the postoperative obstruction of Ando iridectomies is high, as it is reported in up to $32 \%$ of patients. ${ }^{51,52,55,77,78}$ If removal of SO is not desired, reopening by means of neodymium-doped yttrium aluminum garnet (Nd:YAG) laser is indicated. Since failure to reopen Ando iridectomies using the Nd:YAG laser is not uncommon, ${ }^{79}$ a large surgical iridectomy may be required. In cases of heavy tamponades, prophylactic peripheral iridectomy should be performed at the 12-o'clock position. Aqueous suppressants should be accompanied by extensive antiinflammatory therapy.

While pupillary block is well recognized in aphakic eyes, it may also occur in phakic and pseudophakic eyes, probably due to zonular weakness. ${ }^{74,75}$ Hence, a prophylactic iridectomy should be performed intraoperatively in pseudophakic eyes, and it may be also indicated in some phakic eyes. Care must be taken by the surgeon to avoid overfilling of the SO, favoring migration in the anterior segment and obstruction of the aqueous outflow.

A common mechanism inducing the intermediate- or late-onset elevation of IOP is the migration of emulsified $\mathrm{SO}$ in the anterior chamber, which may block or infiltrate the trabecular meshwork..$^{47,52,54-56,60,62-65,69}$ This type of secondary open-angle glaucoma may be associated with a trabeculitis. It has been demonstrated that emulsified SO may be sequestered in various ocular tissues, inducing localized inflammation mediated by macrophages. ${ }^{80,81}$ Other possible mechanisms of late-onset glaucoma include chronic inflammation, ${ }^{52}$ angle closure by synechiae formation, ${ }^{47,56,64}$ or neovascular glaucoma occurring usually in cases of ischemic ocular disorders complicated by secondary retinal detachment, such as diabetes. ${ }^{55,57,73}$ 
Emulsification is characterized by the breakdown of the integrity of the SO bubble into smaller droplets, which can be identified by the slit lamp in the anterior chamber or by gonioscopy at the angle, appearing like "fish eggs." These SO droplets are usually detected a few months after PPVSOI and should be differentiated from inflammatory cells. If emulsification is extensive, it can be manifested as an "inverse hypopyon," which is visualized in the upper part of the anterior chamber.

It has been previously reported that some degree of emulsification may be detected at the slit lamp in up to $100 \%$ of eyes with SO left in place for 1 year; ${ }^{51}$ however, in more recent studies, the incidence of emulsified SO in the anterior chamber is found to be lower. ${ }^{53,55,57,60}$ In a caseseries of 150 eyes with complicated retinal detachment of various etiology that underwent PPV using 1000 centistokes $\mathrm{SO}$, Honavar et $\mathrm{a}^{55}$ reported the overall incidence of SO emulsification at $50 \%$. Jonas et al ${ }^{57}$ observed emulsified SO in the anterior chamber in approximately $22 \%$ of 160 eyes with PVR after PPV using 5000 centistokes of SO injection, in a mean period of 10 months before the removal of SO. The differences between the reported $\mathrm{SO}$ emulsification rates may be explained by variations in the technique of silicone filling, the postoperative course of the underlying pathology, and the quality of SO used. It is suggested that the incidence of $\mathrm{SO}$ emulsification is lower by using the higher-viscosity SO (5000 centistokes) compared to the lower-viscosity SO (1000 centistokes). ${ }^{60,66-68}$

The presence of emulsified SO in the anterior chamber has been associated with IOP elevation. ${ }^{47,55,57,64}$ It has been observed that as long as the SO tamponade was in place, patients with $\mathrm{SO}$ emulsification had slightly higher IOP readings than did patients without $\mathrm{SO}$ emulsification. ${ }^{57}$ Nowack et $\mathrm{a}^{88}$ found that the IOP normalized after removal of the emulsified SO from eyes with increased IOP.

Other investigators could not reveal a significant relationship between the presence of emulsified SO in the anterior

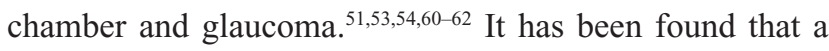
significant number of eyes with SO droplets in the anterior chamber may not have elevated IOP. ${ }^{55,62,82}$ Valone and McCarthy ${ }^{54}$ demonstrated that in the setting of angle SO emulsification, glaucoma developed in $10 \%$ of 48 consecutive eyes after PPVSOI, followed for at least 1 year. It has also been reported that the increase in IOP was independent of the duration of $\mathrm{SO}$ endotamponade. ${ }^{57,69}$

It can be assumed that emulsified $\mathrm{SO}$ in the anterior chamber plays a causative role in the increase of IOP; however, additional factors may determine the onset and magnitude of
IOP elevation leading to glaucomatous damage. In addition to glaucomatous pressure-dependent optic neuropathy, there may also be a direct toxic effect of SO on the optic nerve. ${ }^{83}$

Treatment of glaucoma is generally medical, and can include topical or systemic aqueous humor suppressants. Prostaglandin analogues are less frequently used as firstline therapy postoperatively due to concerns about inducing intraocular inflammation and cystoid macular edema. ${ }^{84,85}$ Current evidence suggests that prostaglandin analogues may also be used in uveitic glaucoma, when other topical treatments could not reduce IOP to the patient's target range. ${ }^{86}$ Depending on the severity of the glaucoma, topical steroids or nonsteroidal antiinflammatory agents may be also required. It has been previously reported that glaucoma was controlled with medicines alone in only $30 \%$ of patients; $; 5$ however, recent data showed that medical therapy by means of topical or oral antiglaucomatous agents was effective in up to $78 \%$ of the eyes, which developed elevated IOP after PPVSOI. ${ }^{54,57,59,60}$

If the medical therapy fails to control IOP, surgical management is required. There is a lack of evidence-based data regarding the optimal surgical intervention. The indications for the removal of SO alone or in combination with an antiglaucomatous procedure have not been clarified yet. It has been previously suggested that the early removal of SO may yield a lower rate of anterior segment complications despite the risk of recurrent retinal detachment. ${ }^{47,65,69,87,88}$ Jonas et $a{ }^{57}$ reported that the emulsification-related increase in IOP was reversible in the vast majority of eyes after the removal of SO. The authors suggested that SO removal may be preferred to invasive antiglaucoma surgery in order to reduce the IOP. Conversely, evidence in the literature supports the fact that the removal of emulsified SO usually failed to control IOP elevation, and may not change the aggressive course of glaucoma in these eyes. ${ }^{55,63,89}$ Budenz et $\mathrm{a}^{164}$ concluded that eyes which undergo $\mathrm{SO}$ removal alone to manage IOP elevation may possibly require a reoperation for glaucoma. They also found that eyes who undergo concurrent SO removal and glaucoma surgery are linked to postoperative hypotony.

All these data suggest that SO removal can not necessarily provide IOP control. The prolonged contact of $\mathrm{SO}$ with the trabecular meshwork may cause structural changes due to infiltration of oil microglobules, resulting in sustained IOP rise, despite SO removal; often, these SO droplets can be detected only by gonioscopy. Thus, it is advisable to follow patients with SO tamponade carefully and to consider SO removal in eyes with emulsified $\mathrm{SO}$ and low risk of retinal 
redetachment. Nevertheless, the surgical management of these patients should be customized according to the individual clinical evaluation. Parameters such as gonioscopic findings, IOP level, onset and duration of IOP elevation, status of posterior segment or visual function, and prognosis should be assessed in order to determine the appropriate surgical approach.

Transscleral cyclophotocoagulation (TCPC) or glaucoma drainage devices (GDD) may represent treatment options in patients with medically uncontrolled glaucoma after PPVSOI. Conventional filtration surgery is associated with poor prognosis due to alterations of the conjunctiva from prior vitreoretinal procedures. ${ }^{62}$ TCPC is an established treatment modality for different types of refractory glaucoma. ${ }^{90}$ Successful IOP control has been reported in up to $82 \%$ of patients at 1 year. This treatment can also be used in eyes with retained SO tamponade..$^{62,91-94}$ The experience of the endoscopic cyclophotocoagulation is limited, but it could be a future treatment modality, especially for eyes requiring $\mathrm{SO}$ removal and antiglaucomatous intervention. ${ }^{95}$

GDDs may be another useful alternative. Ahmed valve implantation has been reported to be a safe and effective method for refractory glaucoma following vitrectomy; ${ }^{96}$ however, the presence of SO has been associated with increased risk of surgical failure in eyes treated with the GDDs. ${ }^{97}$ The use of GDDs implanted superiorly led to the unusual complication of SO escape into the subconjunctival space. ${ }^{98-100}$ If $\mathrm{SO}$ remains in the eye, it is preferred that the GDDs are positioned in one of the inferior quadrants. Al-Jazzaf et $\mathrm{al}^{60}$ performed Ahmed glaucoma shunt implantation with inferotemporal placement of the plate and tube to reduce the chance of SO flowing into the tube. The authors found a cumulative probability of success of $76 \%$ at 1 year after implantation. They also observed SO at the tip of the tube in approximately one-quarter of the patients. ${ }^{100}$ Long-term follow-up and comparative studies to evaluate the effectiveness of TCPC and GDDs are encouraged.

\section{Conclusion}

IOP elevation can occur at any time after vitreoretinal surgery, ranging from mild to severe, or from transient to permanent, and may lead to serious glaucomatous damage. Secondary glaucoma may be associated with various abnormal ocular parameters, which may complicate clinical assessment. Careful postoperative monitoring is required. Diagnosing the mechanism of IOP elevation helps guide the appropriate management. It is essential to determine an individualized target IOP in order to prevent further vision loss, since progressive cupping of the optic disc has been identified, despite IOP reduction. ${ }^{59}$ Suitable IOP control can be achieved with medical treatment in the majority of patients. In persisting cases, laser or surgical treatment is usually effective. Although improvement in surgical techniques and materials has considerably decreased the incidence of glaucoma after vitreoretinal procedures, there are still some controversies regarding optimal management, which may need prospective evaluation to be addressed. Cooperation between vitreoretinal and glaucoma specialists is necessary to obtain successful treatment.

\section{Disclosure}

The authors report no conflicts of interest in this work. The authors have no financial or proprietary interest in any materials or methods described herein.

\section{References}

1. Phelps CD, Burton TC. Glaucoma and retinal detachment. Arch Ophthalmol. 1977;95(3):418-422.

2. Mitchell P, Hourihan F, Sandbach J, Wang JJ. The relationship between glaucoma and myopia: the Blue Mountains Eye Study. Ophthalmology. 1999;106(10):2010-2015.

3. Mitry D, Charteris DG, Fleck BW, Campbell H, Singh J. The epidemiology of rhegmatogenous retinal detachment: geographical variation and clinical associations. Br J Ophthalmol. 2010;94(6):678-684.

4. Pape LG, Forbes M. Retinal detachment and miotic therapy. Am J Ophthalmol. 1978;85(4):558-566.

5. Weseley P, Liebmann J, Walsh JB, Ritch R. Lattice degeneration of the retina and the pigment dispersion syndrome. Am J Ophthalmol. 1992;114(5):539-543.

6. Armaly MF. Effect of corticosteroids on intraocular pressure and fluid dynamics. I. The effect of dexamethasone in the normal eye. Arch Ophthalmol. 1963;70:482-491.

7. Becker B. Intraocular pressure response to topical corticosteroids. Invest Ophthalmol. 1965;4:198-205.

8. Armaly MF. Effect of corticosteroids on intraocular pressure and fluid dynamics. II. The effect of dexamethasone on the glaucomatous eye. Arch Ophthalmol. 1963;70:492-499.

9. Becker B, Mills DW. Corticosteroids and intraocular pressure. Arch Ophthalmol. 1963;70:500-507.

10. Becker B, Hahn KA. Topical corticosteroids and heredity in primary open-angle glaucoma. Am J Ophthalmol. 1964;54:543-551.

11. Gatson H, Absolon MJ, Thurtle OA, Sattar MA. Steroid responsiveness in connective tissue diseases. Br J Ophthalmol. 1983;67(7):487-490.

12. Podos SM, Becker B, Morton WR. High myopia and primary openangle glaucoma. Am J Ophthalmol. 1966;62(6):1038-1043.

13. Shammas HF, Halasa AH, Faris BM. Intraocular pressure, cupdisc ratio, and steroid responsiveness in retinal detachment. Arch Ophthalmol. 1976;94(7):1108-1109.

14. Cantrill HL, Palmberg PF, Zink HA, Waltman SR, Podos SM, Becker B. Comparison of in vitro potency of corticosteroids with ability to raise intraocular pressure. Am J Ophthalmol. 1975;79(6):1012-1017.

15. Sebestyen JG, Schepens CL, Rosenthal ML. Retinal detachment and glaucoma. I. Tonometric and gonioscopic study of 160 cases. Arch Ophthalmol. 1962;67(6):736-745.

16. Hartley RE, Marsh RJ. Anterior chamber depth changes after retinal detachment. Br J Ophthalmol. 1973;57(8):546-550.

17. Kreiger AE, Hodgkinson BJ, Frederick AR Jr, Smith TR. The results of retinal detachment surgery. Analysis of 268 operations with a broad scleral buckle. Arch Ophthalmol. 1971;86(4):385-394. 
18. Perez RN, Phelps CD, Burton TC. Angle-closure glaucoma following scleral buckling operations. Trans Sect Ophthalmol Am Academy Ophthalmol Otolaryng. 1976;81(2):247-252.

19. Hayreh SS, Baines JA. Occlusion of the vortex veins. An experimental study. Br J Ophthalmol. 1973;57(4):217-238.

20. Diddie KR, Ernest JT. Uveal blood flow after 360 degrees constriction in the rabbit. Arch Ophthalmol. 1980;98(4):729-730.

21. Kawana K, Okamoto F, Hiraoka T, Oshika T. Ciliary body edema after scleral buckling surgery for rhegmatogenous retinal detachment. Ophthalmology. 2006;113(1):36-41.

22. Goezinne F, La Heij EC, Berendschot TT, et al. Anterior chamber depth is significantly decreased after scleral buckling surgery. Ophthalmology. 2010;117(1):79-85.

23. Burton TC, Folk JC. Laser iris retraction for angle-closure glaucoma after retinal detachment surgery. Ophthalmology. 1988;95(6):742-748.

24. Sidoti PA, Minckler DS, Baerveldt G, Lee PP, Heuer DK. Aqueous tube shunt to a preexisting episcleral encircling element in the treatment of complicated glaucomas. Ophthalmology. 1994;101(6):1036-1043.

25. Smith MF, Doyle JW, Fanous MM. Modified aqueous drainage implants in the treatment of complicated glaucomas in eyes with pre-existing episcleral bands. Ophthalmology. 1998;105(12):2237-2242.

26. Scott IU, Gedde SJ, Budenz DL, et al. Baerveldt drainage implants in eyes with a preexisting scleral buckle. Arch Ophthalmol. 2000;118(11): 1509-1513.

27. Chang S. Intraocular gases. In: Ryan SJ, editor. Retina, 2nd ed. St Louis, MO: Mosby; 1994:2115-2129.

28. Abrams GW, Edelhauser HF, Aaberg TM, Hamilton LH. Dynamics of intravitreal sulfur hexafluoride gas. Invest Ophthalmol. 1974;13(11) $863-868$

29. Lincoff A, Haft D, Liggett P, Reifer C. Intravitreal expansion of perfluorocarbon bubbles. Arch Ophthalmol. 1980;98(9):1646.

30. Sinawat S, Ratanapakorn T, Sanguansak T, Prompol S, Laopaiboon M, Yospaiboon Y.Airvs perfluorocarbon gas in pneumatic retinopexy: a randomized noninferiority trial. Arch Ophthalmol. 2010;128(10): 1243-1247.

31. Killey FP, Edelhauser HF, Aaberg TM. Intraocular sulfur hexafluoride and octofluorocyclobutane. Arch Ophthalmol. 1978;96(3):511-515.

32. Abrams GW, Swanson DE, Sabates WI, Goldman AI. The results of sulfur hexafluoride gas in vitreous surgery. Am J Ophthalmol. 1982;94(2):165-171

33. Chang S, LincoffHA, Coleman DJ, Fuchs W, Farber ME. Perfluorocarbon gases in vitreous surgery. Ophthalmology. 1985;92(5):651-656.

34. Vitrectomy with silicone oil or sulfur hexafluoride gas in eyes with severe proliferative vitreoretinopathy: results of a randomized clinical trial. Silicone Study Report 1. Arch Ophthalmol. 1992;110(6):770-779.

35. [No authors listed] Vitrectomy with silicone oil or perfluoropropane gas in eyes with severe proliferative vitreoretinopathy: results of a randomized clinical trial. Silicone Study Report 2. Arch Ophthalmol. 1992;110(6):780-792.

36. Dieckert JP, O'Connor PS, Schacklett DE, et al. Air travel and intraocular gas. Ophthalmology. 1986;93(5):642-645.

37. Lincoff H, Weinberger D, Reppucci V, Lincoff A. Air travel with intraocular gas: I. The mechanisms for compensation. Arch Ophthalmol. 1989;107(6):902-906.

38. Kokame GT, Ing MR. Intraocular gas and low-altitude air flight. Retina 1994;14(4):356-358

39. Poliner LS, Schoch LH. Intraocular pressure assessment in gas-filled eyes following vitrectomy. Arch Ophthalmol. 1987;105(2):200-202.

40. Hines MW, Jost BF, Fogelman KL. Oculab Tono-Pen, Goldmann applanation tonometry, and pneumatic tonometry for intraocular pressure assessment in gas-filled eyes. Am J Ophthalmol. 1988;106(2):174-179.

41. Lim JI, Blair NP, Higginbotham EJ, Farber MD, Shaw WE, Garretson BR. Assessment of intraocular pressure in vitrectomized gascontaining eyes. A clinical and manometric comparison of the Tono-Pen to the pneumotonometer. Arch Ophthalmol. 1990;108(5):684-688.

42. Bartz-Schmidt KU, Kirchhof B, Heimann K. Primary vitrectomy for pseudophakic retinal detachment. Br J Ophthalmol. 1996;80(4): 346-349.
43. Kaynak S, Tekin NF, Durak I, Berk AT, Saatci AO, Soylev MF. Pars plana vitrectomy with pars plana tube implantation in eyes with intractable glaucoma. Br J Ophthalmol. 1998;82(12):1377-1382.

44. Scott IU, Alexandrakis G, Flynn HW Jr, et al. Combined pars plana vitrectomy and glaucoma drainage implant placement for refractory glaucoma. Am J Ophthalmol. 2000;129(3):334-341.

45. Cibis PA, Becker B, Okun E, Canaan S. The use of liquid silicone in retinal detachment surgery. Arch Ophthalmol. 1962;68:590-599.

46. Faulborn J, Conway BP, Machemer R. Surgical complications of pars plana vitreous surgery. Ophthalmology. 1978;85(2):116-125.

47. Leaver PK, Grey RH, Garner A. Silicone oil injection in the treatment of massive preretinal retraction. II. Late complications in 93 eyes. $\mathrm{Br}$ J Ophthalmol. 1979;63(5):361-367.

48. Weinberg RS, Peyman GA, Huamonte FU. Elevation of intraocular pressure after pars plana vitrectomy. Albrecht Von Graefes Klin Exp Ophthalmol. 1976;200(2):157-161.

49. McCuen BW 2nd, de Juan E Jr, Landers MB 3rd, Machemer R. Silicone oil in vitreoretinal surgery. Part 2: Results and complications. Retina. 1985;5(4):198-205.

50. Lucke KH, Foerster MH, Laqua H. Long-term results of vitrectomy and silicone oil in 500 cases of complicated retinal detachments. $\mathrm{Am} \mathrm{J}$ Ophthalmol. 1987;104(6):624-633.

51. Federman JL, Schubert HD. Complications associated with the use of silicone oil in 150 cases after retina-vitreous surgery. Ophthalmology. 1988;95(7):870-876.

52. Riedel KG, Gabel VP, Neubauer L, Kampik A, Lund OE. Intravitreal silicone oil injection: complications and treatment of 415 consecutive patients. Graefes Arch Clin Exp Ophthalmol. 1990; 228(1):19-23.

53. Barr CC, Lai MY, Lean JS, et al. Postoperative intraocular pressure abnormalities in the Silicone Study. Silicone Study Report 4. Ophthalmology. 1993;100(11):1629-1635.

54. Valone J Jr, McCarthy M. Emulsified anterior chamber silicone oil and glaucoma. Ophthalmology. 1994;101(12):1908-1912.

55. Honavar SG, Goyal M, Majji AB, Sen PK, Naduvilath T, Dandona L. Glaucoma after pars plana vitrectomy and silicone oil injection for complicated retinal detachments. Ophthalmology. 1999;106(1):169-176; discussion 177.

56. Henderer JD, Budenz DL, Flynn HW Jr, Schiffman JC, Feuer WJ, Murray TG. Elevated intraocular pressure and hypotony following silicone oil retinal tamponade for complex retinal detachment: incidence and risk factors. Arch Ophthalmol. 1999;117(2):189-195.

57. Jonas JB, Knorr HL, Rank RM, Budde WM. Intraocular pressure and silicone oil endotamponade. J Glaucoma. 2001;10(2):102-108.

58. Gedde SJ. Management of glaucoma after retinal detachment surgery. Curr Opin Ophthalmol. 2002;13(2):103-109.

59. Tranos P, Asaria R, Aylward W, Sullivan P, Franks W. Long term outcome of secondary glaucoma following vitreoretinal surgery. $\mathrm{Br} \mathrm{J}$ Ophthalmol. 2004;88(3):341-343.

60. Al-Jazzaf AM, Netland PA, Charles S. Incidence and management of elevated intraocular pressure after silicone oil injection. J Glaucoma. 2005;14(1):40-46.

61. Watzke RC. Silicone retinopiesis for retinal detachment. A long-term clinical evaluation. Arch Ophthalmol. 1967;77(2):185-196.

62. Nguyen QH, Lloyd MA, Heuer DK, et al. Incidence and management of glaucoma and intravitreal silicone oil injection for complicated retinal detachments. Ophthalmology. 1992;99(10):1520-1526.

63. Moisseiev J, Barak A, Manaim T, Treister G. Removal of silicone oil in the management of glaucoma in eyes with emulsified silicone. Retina. 1993;13(4):290-295.

64. Budenz DL, Taba KE, Feuer WJ, et al. Surgical management of secondary glaucoma after pars plana vitrectomy and silicone oil injection for complex retinal detachment. Ophthalmology. 2001;108(9): 1628-1632.

65. La Heij EC, Hendrikse F, Kessels AG. Results and complications of temporary silicone oil tamponade in patients with complicated retinal detachments. Retina. 2001;21(2):107-114. 
66. Petersen J, Ritzau-Tondrow U. Chronisches Glaukom nach Silikonölimplantation: Zwei Öle verschiedener Viskosität im Vergleich [Chronic glaucoma following silicone oil implantation: a comparison of 2 oils of differing viscosity.] Fortschr Ophthalmol. 1988;85(6):632-634. German.

67. Heidenkummer HP, Kampik A, Thierfelder S. Experimental evaluation of in vitro stability of purified polydimethylsiloxanes (silicone oil) in viscosity ranges from 1000 to 5000 centistokes. Retina. 1992; 12(Suppl 3):S28-S32.

68. Lakits A, Nennadal T, Scholda C, Knaus S, Gruber H. Chemical stability of silicone oil in the human eye after prolonged clinical use. Ophthalmology. 1999;106(6):1091-1100.

69. Gonvers M, Andenmatten R. Temporary silicone oil tamponade and intraocular pressure: an 11-year retrospective study. Eur J Ophthalmol. 1996;6(1):74-80.

70. Joussen AM, Wong D. The concept of heavy tamponadeschances and limitations. Graefes Arch Clin Exp Ophthalmol. 2008; 246(9):1217-1224.

71. Joussen AM, Rizzo S, Kirchhof B, et al; for HSO-Study Group. Heavy silicone oil versus standard silicone oil in as vitreous tamponade in inferior PVR (HSO Study): interim analysis. Acta Ophthalmol. 2011;89(6):e483-e489.

72. Ichhpujani P, Jindal A, Jay Katz L. Silicone oil induced glaucoma: a review. Graefes Arch Clin Exp Ophthalmol. 2009;247(12):1585-1593.

73. de Corral LR, Cohen SB, Peyman GA. Effect of intravitreal silicone oil on intraocular pressure. Ophthalmic Surg. 1987;18(6): 446-449.

74. Zborowski-Gutman L, Treister G, Naveh N, Chen V, Blumenthal M. Acute glaucoma following vitrectomy and silicone oil injection. $\mathrm{Br} J$ Ophthalmol. 1987;71(12):903-906.

75. Jackson TL, Thiagarajan M, Murthy R, Snead MP, Wong D, Williamson TH. Pupil block glaucoma in phakic and pseudophakic patients after vitrectomy with silicone oil injection. Am J Ophthalmol. 2001;132(3):414-416.

76. Ando F. Intraocular hypertension resulting from pupillary block by silicone oil. Am J Ophthalmol. 1985;99(1):87-88.

77. Beekhuis WH, Ando F, Zivojnović R, Mertens DA, Peperkamp E. Basal iridectomy at 6 o'clock in the aphakic eye treated with silicone oil: prevention of keratopathy and secondary glaucoma. Br J Ophthalmol. 1987;71(3):197-200.

78. Madreperla SA, McCuen BW 2nd. Inferior peripheral iridectomy in patients receiving silicone oil. Rates of postoperative closure and effect on oil position. Retina. 1995;15(2):87-90.

79. Reddy MA, Aylward GW. The efficacy of neodymium: YAG laser iridotomy in the treatment of closed peripheral iridotomies in siliconeoil-filled aphakic eyes. Eye (Lond). 1995;9(Pt 6):757-759.

80. Suzuki M, Okada T, Takeuchi S, Ishii Y, Yamashita H, Hori S. Effect of silicone oil on ocular tissues. Jpn J Ophthalmol. 1991;35(3): 282-291.

81. Wickham L, Asaria RH, Alexander R, Luthert P, Charteris DG. Immunopathology of intraocular silicone oil: enucleated eyes. $\mathrm{Br} J$ Ophthalmol. 2007;91(2):253-257.

82. Laroche L, Pavlakis C, Saraux H, Orcel L. Ocular findings following intravitreal silicone injection. Arch Ophthalmol. 1983;101(9): $1422-1425$.

Clinical Ophthalmology

\section{Publish your work in this journal}

Clinical Ophthalmology is an international, peer-reviewed journal covering all subspecialties within ophthalmology. Key topics include: Optometry; Visual science; Pharmacology and drug therapy in eye diseases; Basic Sciences; Primary and Secondary eye care; Patient Safety and Quality of Care Improvements. This journal is indexed on Submit your manuscript here: http://www.dovepress.com/clinical-ophthalmology-journal
83. Budde M, Cursiefen C, Holbach LM, Naumann GO. Silicone oil-associated optic nerve degeneration. Am J Ophthalmol. 2001;131(3):392-394.

84. Susanna R Jr, Medeiros FA. The pros and cons of different prostanoids in the medical management of glaucoma. Curr Opinion Ophthalmol. 2001;12(2):149-156.

85. Alm A, Grierson I, Shields MB. Side effects associated with prostaglandin analog therapy. Surv Ophthalmol. 2008;53 Suppl 1:S93-S105.

86. Horsley MB, Chen TC. The use of prostaglandin analogs in the uveitic patient. Semin Ophthalmol. 2011;26(4-5):285-289.

87. Gao RL, Neubauer L, Tang S, Kampik A. Silicone oil in the anterior chamber. Graefes Arch Clin Exp Ophthalmol. 1989;227(2):106-109.

88. Nowack C, Lucke K, Laqua H. Removal of silicone oil in treatment of so-called emulsification glaucoma. Ophthalmologe. 1992;89(6): 462-464.

89. Flaxel CJ, Mitchell SM, Aylward GW. Visual outcome after silicone oil removal and recurrent retinal detachment repair. Eye (Lond). 2000;14(Pt 6):834-838.

90. Iliev ME, Gerber S. Long-term outcome of trans-scleral diode laser cyclophotocoagulation in refractory glaucoma. Br J Ophthalmol. 2007;91(12):1631-1635.

91. Bloom PA, Tsai JC, Sharma K, et al. "Cyclodiode". Trans-scleral diode laser cyclophotocoagulation in the treatment of advanced refractory glaucoma. Ophthalmology. 1997;104(9):1508-1519; discussion 1519-1520.

92. Han SK, Park KH, Kim DM, Chang BL. Effect of diode laser transscleral cyclophotocoagulation in the management of glaucoma after intravitreal silicone injection for complicated retinal detachments. $\mathrm{Br}$ J Ophthalmol. 1999;83(6):713-717.

93. Kumar A, Dada T, Singh RP, Kedar S. Diode laser trans-scleral cyclophotocoagulation for glaucoma following silicone oil removal. Clin Experiment Ophthalmol. 2001;29(4):220-224.

94. Ghazi-Nouri SM, Vakalis AN, Bloom PA, Bunce C, Charteris DG. Long-term results of the management of silicone oil-induced raised intraocular pressure by diode laser cycloablation. Eye (Lond). 2005;19(7):765-769.

95. Lin S. Endoscopic cyclophotocoagulation. Br J Ophthalmol. 2002; 86(12):1434-1438.

96. Hong JW, Choi GJ. Ahmed valve implantation for refractory glaucoma following pars plana vitrectomy. Korean J Ophthalmol. 2005;19(4): 293-296.

97. Ishida K, Ahmed II, Netland PA. Ahmed glaucoma valve surgical outcomes in eyes with and without silicone oil endotamponade. J Glaucoma. 2009;18(4):325-330.

98. Hyung SM, Min JP. Subconjunctival silicone oil drainage through the Molteno implant. Korean J Ophthalmol. 1998;12(1):73-75.

99. Nazemi PP, Chong LP, Varma R, Burnstine MA. Migration of intraocular silicone oil into the subconjunctival space and orbit through an Ahmed glaucoma valve. Am J Ophthalmol. 2001;132(6):929-931.

100. Morales J, Shami M, Craenen, Wentlandt TF. Silicone oil egressing through an inferiorly implanted ahmed valve. Arch Ophthalmol. 2002;120(6):831-832
PubMed Central and CAS, and is the official journal of The Society of Clinical Ophthalmology (SCO). The manuscript management system is completely online and includes a very quick and fair peer-review system, which is all easy to use. Visit http://www.dovepress.com/ testimonials.php to read real quotes from published authors. 